\title{
Leukocyte Sequestration in Pulmonary Microvessels and Lung Injury following Systemic Complement Activation in Rabbits
}

\author{
Gerhard E.H. Kuhnle ${ }^{a}$ Rainer Kiefmanna Axel Sckell ${ }^{b}$ \\ Wolfgang M. Kueblerb Joachim Groh ${ }^{\mathrm{a}}$ Alwin E. Goetz ${ }^{\mathrm{a}}$ \\ ${ }^{a}$ Department of Anesthesiology and ${ }^{b}$ Institute for Surgical Research, University of Munich, Germany
}

\section{Key Words}

Pulmonary microcirculation - Leukocytes - Microscopy · Complement activation - Cobra venom

\begin{abstract}
Inflammatory reactions are associated with sequestration of leukocytes in the lung. Complement activation leads to accumulation of leukocytes in alveolar septa and alveoli, to lung edema and hemorrhage. Although in organs other than the lung leukocytes interact with the vascular endothelium only in postcapillary venules, alveolar capillaries are considered to be the site of leukocyte sequestration in the lung. However, pulmonary venules and arterioles have not been investigated systematically after complement activation so far. A closed thoracic window was implanted in anesthetized rabbits; leukocytes and red blood cells were stained, and the movement of these cells was measured in superficial pulmonary arterioles, venules and alveolar capillaries using fluorescence video microscopy before and 30 and $60 \mathrm{~min}$ after infusion of cobra venom factor (CVF). Erythrocyte velocity and macrohemodynamic conditions did not change after CVF infusion and were not different from
\end{abstract}

\begin{tabular}{ll}
\hline KARGER & ( 1999 S. Karger AG, Basel \\
Fax +4161306 12 34 & Accessible online at: \\
$\begin{array}{l}\text { E-Mail karger@karger.ch } \\
\text { www.karger.com }\end{array}$ & http://BioMedNet.com/karger
\end{tabular}

the sham-treated controls. The number of sticking leukocytes increased significantly compared to baseline and control: by $150 \%$ in arterioles and in venules and by $740 \%$ in alveolar capillaries within 60 min after CVF infusion. The width of alveolar septa in vivo was significantly enlarged after CVF infusion, indicating interstitial pulmonary edema. At the end of the experiments, myeloperoxidase activity was higher in the CVF group, showing leukocyte sequestration in the whole organ. It is concluded that complement activation by CVF induces leukocyte sequestration in lung arterioles, venules and alveolar capillaries and leads to mild lung injury.

\section{Introduction}

Acute lung injury after activation of complement is of clinical significance after extracorporeal circulation in cardiac surgery [1]. Moreover, complement activation and subsequent sequestration of leukocytes in the lung are suggested as causative factors in the development of lung injury, after ischemia and reperfusion or during sepsis [2, 3]. In a model of acute lung injury, complement activation

Dr. G. Kuhnle

Department of Anesthesiology, Klinikum Grosshadern, University of Munich Marchioninistrasse 15, D-81366 Munich (Germany)

Tel. +49897095 1, Fax +498970958886

E-Mail Gerhard.Kuhnle@ana.med.uni-muenchen.de 
by intravenous cobra venom factor (CVF) leads to sequestration of leukocytes in the lung and to lung edema and hemorrhage within $30 \mathrm{~min}$ [4]. Leukocyte sequestration as well as lung injury were inhibited in that model by pretreatment with monoclonal antibodies against leukocyte and endothelial adhesion molecules [5, 6]. Histologically, sequestered leukocytes were found mainly in alveolar capillaries. Also, using intravital microscopy, leukocytes were observed only in capillaries after intratracheal or pulmonary arterial injection of complement-derived chemotactic fragments $[7,8]$. The most popular explanation for leukocyte accumulation in capillaries is a discrepancy between cell and vessel diameter, which forces the leukocytes to deform and delays their passage in capillaries [9-12]. However, leukocyte-endothelium interactions mediated by adhesion molecules have been observed only in postcapillary venules and not in capillaries in organs other than the lungs [13]. This raises the question whether leukocyteendothelium interaction only in capillaries was the target of antiadhesion therapy in the model of CVF-induced lung injury, or whether adhesion in pulmonary venules was inhibited. Indeed, we and others have recently shown that leukocytes may also roll on and stick to the endothelium of pulmonary postcapillary venules and precapillary arterioles under physiological conditions as well as after pulmonary ischemia and reperfusion [14-18]. Thus, leukocyte adhesion in pulmonary venules may effectively play a significant role in the development of lung injury. However, with the exception of one study using leukocytes labeled in vitro [7], the kinetics of leukocytes in pulmonary arterioles and venules after complement activation have not been investigated systematically so far, and primarily the role of the pulmonary venules in the inflammatory process remains unclear. Therefore, the purpose of the study was to examine the microhemodynamics and the kinetics of leukocytes labeled in vivo after systemic complement activation by intravital microscopy.

\section{Methods}

\section{Experimental Setup}

The experiment was designed to determine the time course and the site of leukocyte sequestration after complement activation by intravenous CVF. Microhemodynamics and the number of sequestered leukocytes were measured $30 \mathrm{~min}$ and $1 \mathrm{~h}$ after injection of CVF in individual pulmonary arterioles, venules and alveolar capillary networks. In parallel to this, macrohemodynamic parameters, arterial blood gases and the width of alveolar septa were measured to determine functional and morphological parameters of lung injury. At the end of the experiments, the lungs were removed and myeloperoxidase (MPO) activity as indicator of the number of neutrophils contained in the lungs was determined.

\section{Animal Preparation}

New Zealand White rabbits were used in this study. The animals were anesthetized with thiopental sodium $(50 \mathrm{mg}$ i.v.) followed by $\alpha$-chloralose ( $50 \mathrm{mg} / \mathrm{kg}$ b.w.). Piritramide $(0.5 \mathrm{mg} / \mathrm{kg}$ b.w.) was given for analgesia and pancuronium bromide $(0.3 \mathrm{mg} / \mathrm{kg}$ b.w.) for neuromuscular blockade. The rabbits were tracheotomized and ventilated mechanically at an $\mathrm{FiO}_{2}$ of 0.3 and an inspiratory pressure of $8 \mathrm{~mm}$ $\mathrm{Hg}$. Catheters were introduced into the aorta for the measurement of systemic arterial pressure, into the superior vena cava for measurement of central venous pressure and into the pulmonary artery for measurement of pulmonary artery pressure. A 5-Fr temperature probe (Arrow, Erding, Germany) was inserted into the descendent aorta to measure cardiac output after intravenous injection of $1 \mathrm{ml}$ of cold $0.9 \%$ sodium chloride solution by the thermodilution method. For intravital microscopy, parts of the left third and fourth rib were removed and a thoracic window was implanted as described previously [19]. The animals were placed in the right lateral position under a fluorescence microscope (Leica, Wetzlar, Germany). To visualize microvascular blood flow, FITC-labeled red blood cells (Sigma, St. Louis, Mo., USA) were infused. Leukocytes were stained in vivo by injection of rhodamine $6 \mathrm{G}(0.06 \mu \mathrm{mol} / \mathrm{kg}$; Merck, Darmstadt, Germany). The green-light-emitting FITC-labeled red cells and the red-light-emitting leukocytes were differentiated under the microscope by switching the emission and excitation filters (I2/3, L2 and N2 filter blocks; Leica, Wetzlar, Germany). The images were recorded on video tape with a silicon-intensified target camera (C 2400, Hamamatsu, Herrsching, Germany). Video recordings were performed during inspiration periods prolonged to 5-10 s to avoid respiratory movement. Prolongation of the inspiration period to more than $15 \mathrm{~s}$ would lead to central venous congestion, bradycardia and to a fall in blood pressure and cardiac output.

\section{Microhemodynamics and Measurement of Leukocyte Kinetics}

The measurements were performed offline using an image-processing system (Optimas, Bioscan, Edmonds, Wash., USA), as described in detail previously $[17,18]$. Briefly, internal diameters of subpleural arterioles and venules were measured as closest distance between the vessel walls, visualized in green fluorescence image. Mean red blood cell velocity was determined as harmonic mean of the velocity of approximately 30 fluorescently labeled red cells passing a predefined vessel cross-section. Sticking, i.e. non moving leukocytes were determined as the number of fluorescent leukocytes not moving for at least $5 \mathrm{~s}$, which was the minimal length of a single observation period during inspiration and long enough to differentiate between rolling and adherent leukocytes. The numbers of sticking leukocytes in arterioles and venules are normalized to the inner vessel surface of the predefined vessel segment. For measurements of microhemodynamics and leukocyte kinetics in alveolar capillaries, the subpleural wall of single alveoli was investigated. The boundaries of the alveolar wall were determined interactively using the image analysis system and the alveolar wall area was measured. For measurement of red blood cell velocity in alveolar capillaries, the transit of approximately 30 labeled red blood cells was followed, and the path and transit time measured. The number of sticking leukocytes in the alveolar capillary network of single alveoli was measured as the number of leukocytes not moving for at least $5 \mathrm{~s}$ and normalized to the alveolar wall area. In addition, the width of alveolar septa was measured as the mean of the closest distance between the investigated alveolar wall area to the adjacent alveoli. At least two arterioles, two venules and five alveolar wall areas were investigated in each experimental phase. 
Table 1. Macrohemodynamics and blood gas analysis

\begin{tabular}{|c|c|c|c|c|c|c|}
\hline & \multicolumn{2}{|l|}{ Baseline } & \multicolumn{2}{|l|}{$30 \mathrm{~min}$} & \multicolumn{2}{|l|}{$1 \mathrm{~h}$} \\
\hline & $\mathrm{CVF}$ & control & $\mathrm{CVF}$ & control & $\mathrm{CVF}$ & control \\
\hline $\mathrm{MAP}, \mathrm{mm} \mathrm{Hg}$ & $90.7 \pm 2.9$ & $86.9 \pm 3.9$ & $83.0 \pm 3.0^{1}$ & $81.8 \pm 1.3$ & $81.5 \pm 4.9$ & $78.0 \pm 2.3$ \\
\hline $\mathrm{CVP}, \mathrm{mm} \mathrm{Hg}$ & $3.1 \pm 1.6$ & $3.1 \pm 0.6$ & $4.7 \pm 1.4$ & $4.2 \pm 0.9$ & $5.3 \pm 1.4$ & $4.0 \pm 0.8$ \\
\hline $\mathrm{PAP}, \mathrm{mm} \mathrm{Hg}$ & $15.6 \pm 2.6$ & $12.0 \pm 1.2$ & $18.9 \pm 4.1$ & $13.0 \pm 1.2$ & $16.4 \pm 2.8$ & $14.7 \pm 2.9$ \\
\hline $\mathrm{CO}, \mathrm{ml} / \mathrm{min}$ & $408 \pm 21^{2}$ & $269 \pm 30$ & $354 \pm 23^{2}$ & $280 \pm 29$ & $373 \pm 22^{2,3}$ & $265 \pm 30$ \\
\hline $\mathrm{PaCO}_{2}, \mathrm{~mm} \mathrm{Hg}$ & $48.0 \pm 6.1$ & $38.6 \pm 2.0$ & $54.5 \pm 6.6$ & $43.0 \pm 2.9$ & $61.5 \pm 11.4$ & $44.2 \pm 3.0$ \\
\hline $\mathrm{PaO}_{2}, \mathrm{~mm} \mathrm{Hg}$ & $152.7 \pm 12.5$ & $148.7 \pm 4.4$ & $127.4 \pm 11.7$ & $148.6 \pm 4.0$ & $131.1 \pm 19.1$ & $149.1 \pm 3.5$ \\
\hline
\end{tabular}

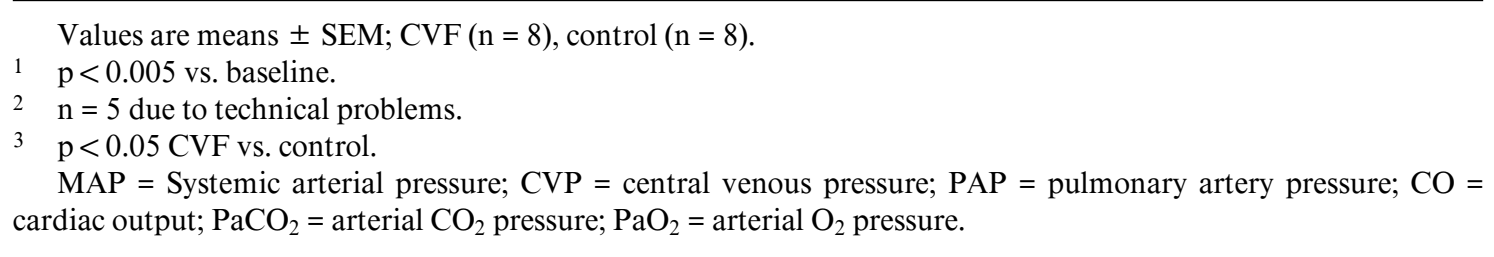

\section{Experimental Protocol}

After the preparation period, the FITC-labeled red blood cells were reinjected and the animal was placed under the microscope. After a stabilization period of $15 \mathrm{~min}$, the animals were randomly assigned to the CVF or the control group. For leukocyte staining rhodamine $6 \mathrm{G}$ was injected. Then baseline video recordings of 2 arterioles, 2 venules and 5 alveolar wall areas were performed, macrohemodynamic parameters recorded and blood for arterial gas analyses taken. The animals then received $0.2 \mathrm{mg} / \mathrm{kg}$ b.w. i.v. purified CVF (kindly provided by D. White, Cambridge, UK) into the central venous catheter or the same volume of saline. Thirty minutes and $1 \mathrm{~h}$ after injection, video recordings of the same vessels and alveolar areas were performed, macrohemodynamic parameters measured and probes for blood gas analysis taken. At the end of the experiments, the animals were sacrificed and the lungs removed for measurement of MPO activity as described earlier in detail [20].

\section{Statistics}

All data are given as mean \pm standard error of the mean. Repeated measurements were tested using the ANOVA for repeated measurements followed by post hoc comparisons (Newman-Keuls test) if significant differences were detected. Comparisons between control and the CVF group were tested using the t test. Statistical significance was assumed for $\mathrm{p}<0.05$. Calculations were performed using the computer program STATISTICA (StatSoft, Inc 1997, Tulsa, Okla., USA).

\section{Results}

\section{Macrohemodynamic Parameters and Blood Gas Measurements}

Table 1 summarizes the results of macrohemodynamic and blood gas measurements. In the CVF group, mean arterial pressure was lower $30 \mathrm{~min}$ after $\mathrm{CVF}$ as compared to baseline, and cardiac output was significantly higher 60 min after CVF as compared to control. Other macrohemodynamic and blood gas parameters were not significantly different between groups. At $30 \mathrm{~min}$ after injection of CVF, the white blood cell count had fallen significantly from $5.0 \pm 0.6 \cdot 10^{6}$ cells/liter at baseline to $2.9 \pm 0.2 \cdot 10^{6}$ and $2.0 \pm 0.3 \cdot 10^{6}$ cells/liter at $30 \mathrm{~min}$ and $1 \mathrm{~h}$ after CVF $(\mathrm{p}<0.0005$ and $\mathrm{p}<0.01)$. The values at $30 \mathrm{~min}$ and $1 \mathrm{~h}$ were significantly lower than in controls $\left(5.7 \pm 0.6 \cdot 10^{6}\right.$, $5.5 \pm 0.5 \cdot 10^{6}$ and $4.6 \pm 1.0 \cdot 10^{6}$ cells/liter) at baseline, 30 and $60 \min (p<0.0005$ and $p<0.05$ CVF vs. control at 30 and $60 \mathrm{~min}$ ). Among leukocytes, the rate of neutrophils fell from $28 \pm 3 \%$ at baseline to $7 \pm 2 \% 30 \mathrm{~min}$ after injection of CVF.

\section{Microhemodynamic Parameters and Leukocyte Kinetics}

For microscopic measurements, arterioles and venules with a diameter of 20-30 $\mu \mathrm{m}$ were investigated. There was no significant difference at baseline between CVF group (arterioles $20.7 \pm 0.9 \mu \mathrm{m}$, venules $23.3 \pm 1.4 \mu \mathrm{m}$ ) and control group (arterioles $21.3 \pm 1.0 \mu \mathrm{m}$, venules $20.5 \pm 1.2$ $\mu \mathrm{m})$. During the experiments, diameters did not change significantly in the CVF group nor in the control group.

Under baseline conditions, mean red blood cell velocity was significantly lower in arterioles than in venules (control: arterioles 1,507 $\pm 101 \mu \mathrm{m} / \mathrm{s}$, venules 1,860 \pm $117 \mu \mathrm{m} / \mathrm{s} ; \mathrm{p}<0.05$; CVF: arterioles 1,309 $\pm 164 \mu \mathrm{m} / \mathrm{s}$, venules $1,808 \pm 138 \mu \mathrm{m} / \mathrm{s} ; \mathrm{p}<0.05)$. These data confirm our previous findings $[14,16,17-19]$ and are explained 


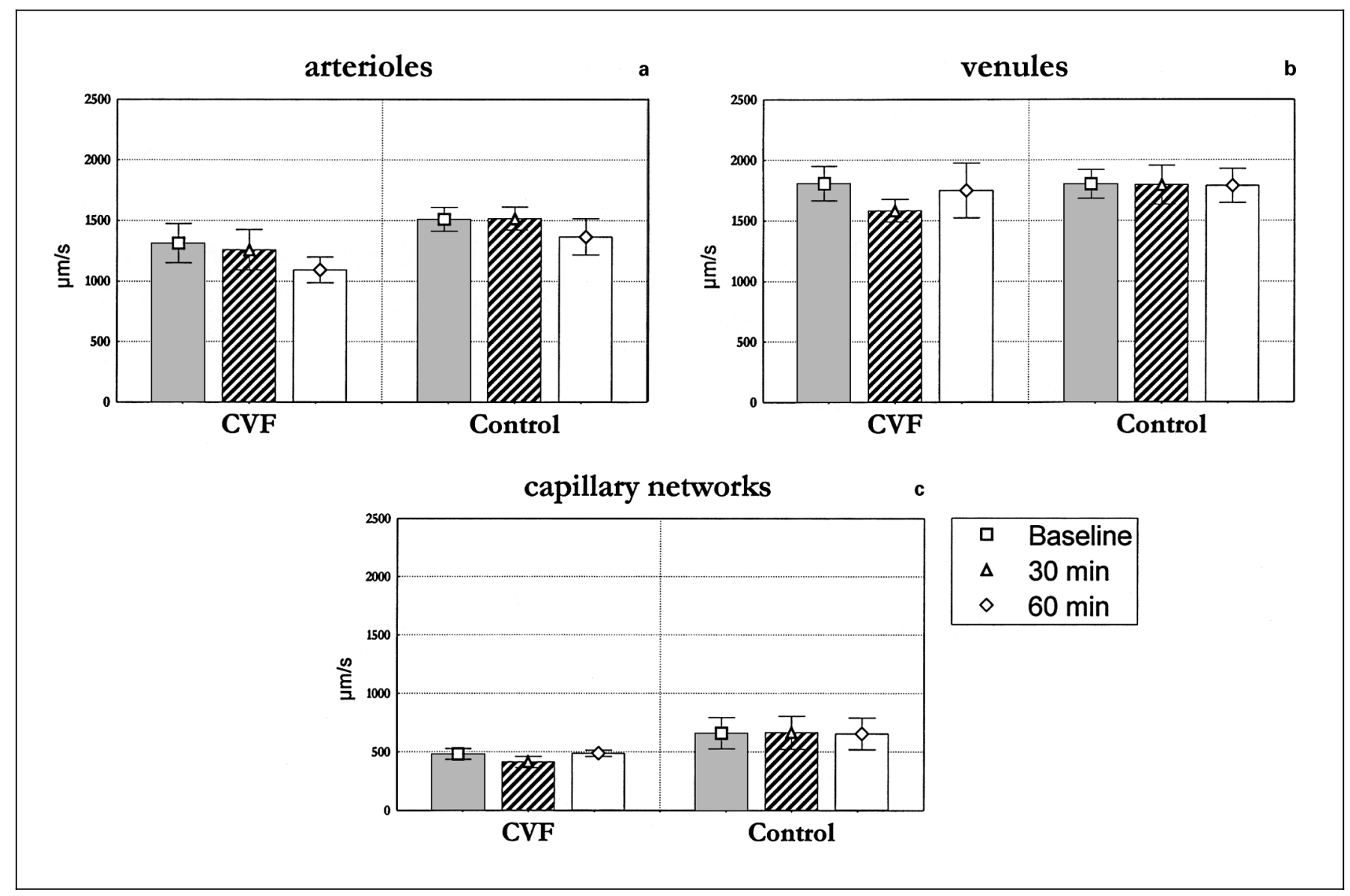

Fig. 1. Mean $\mathrm{RBC}$ velocity in pulmonary arterioles (a), venules (b) and alveolar capillaries (c). Values are means \pm SEM; CVF $(n=8)$, control $(n=8)$; n.s.

by hydrodynamic forces in pulmonary microvessels under zone 2 conditions [21]. In alveolar capillaries, mean red blood cell velocity was markedly lower (control: 527 $\pm 29 \mu \mathrm{m} / \mathrm{s}$; CVF: $482 \pm 45 \mu \mathrm{m} / \mathrm{s}$ ). There was no significant difference between control and CVF group at baseline, neither in arterioles or venules nor in alveolar capillaries. After treatment, mean red blood cell velocity did not change significantly after CVF nor in the control group (fig. 1).

Figure 2 shows the results of measurements of leukocyte kinetics. Despite a higher red blood cell velocity, the number of sticking leukocytes was higher in venules than in arterioles. There was no difference between CVF and control group at baseline. Thirty minutes after injection of CVF or saline there was a $50 \%$ increase in the number of sticking leukocytes in arterioles, a 100\% increase in venules and a 500\% increase in alveolar capillaries. After $1 \mathrm{~h}$, there was a further increase in the number of sticking leukocytes measured in arterioles, venules and alveolar capillaries.

In figure 3, the changes in the width of alveolar septa are shown. At baseline, alveolar septa were on average $17.1 \pm 1.1 \mu \mathrm{m}$ in the control and $16.5 \pm 0.3 \mu \mathrm{m}$ in the CVF group. During the experiment, a significant increase in the width of alveolar septa was noted in the CVF group at $30 \mathrm{~min}$ and at $1 \mathrm{~h}$, whereas the width of alveolar septa in the control group remained unchanged.

At the end of the experiments, the lungs were removed and the MPO activity was measured in both groups. Figure 4 shows the MPO activity of the right and left lung lobe in the control and the CVF group. There was no significant difference between left and right lungs; however, MPO activity in the CVF group was more than double that in the control group. 


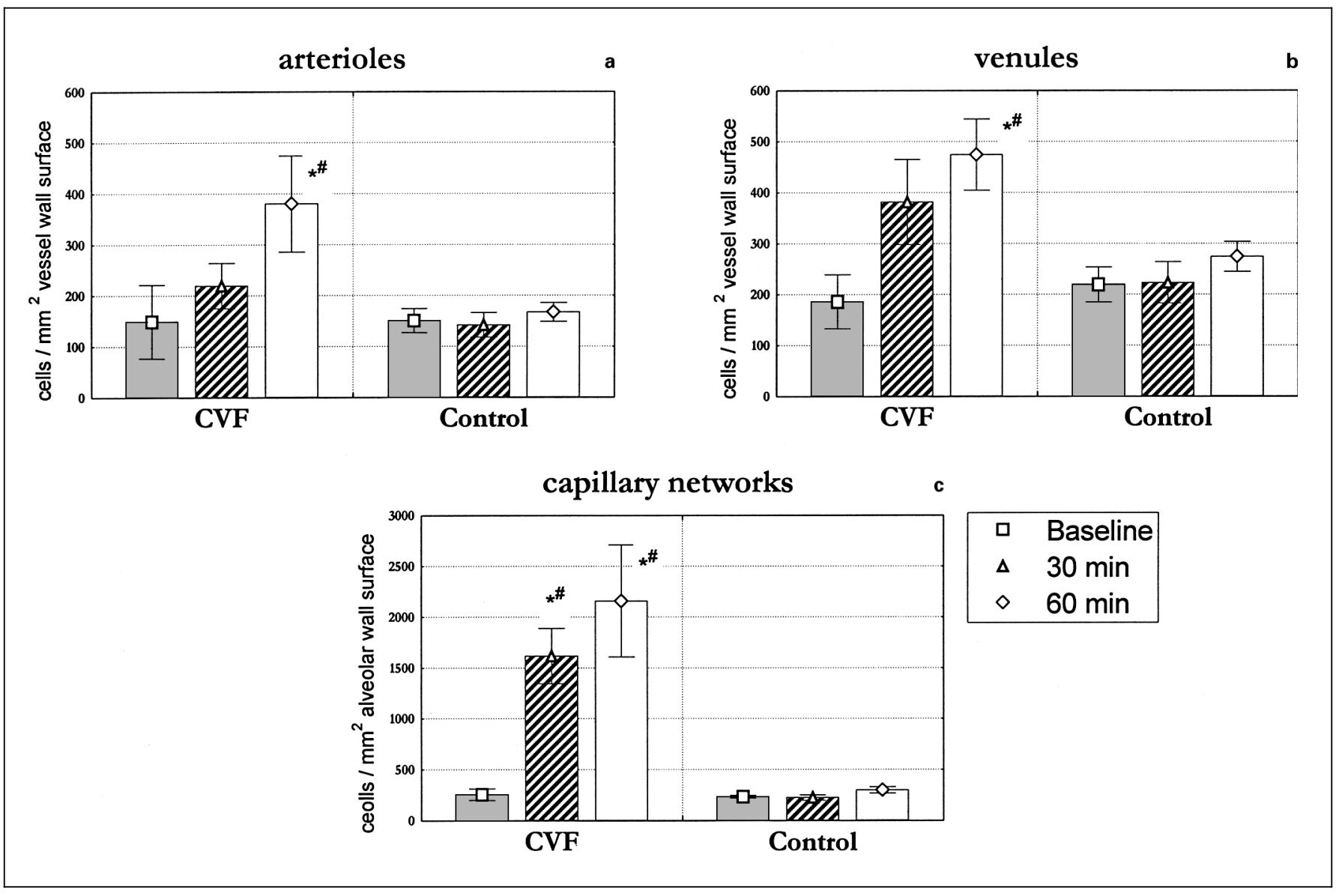

Fig. 2. Sticking leukocytes in pulmonary arterioles (a), venules (b) and alveolar capillaries (c). Values are means \pm SEM; CVF $(n=8)$, control $(n=8) ;{ }^{*} p<0.05$ CVF vs. control; ${ }^{*} p<0.05$ vs. baseline.

Fig. 3. Width of alveolar septa. Values are means \pm SEM; CVF $(n=8)$, control $(n=8)$; $* \mathrm{p}<0.05$ CVF vs. control; \# $\mathrm{p}<0.05$ vs. baseline.

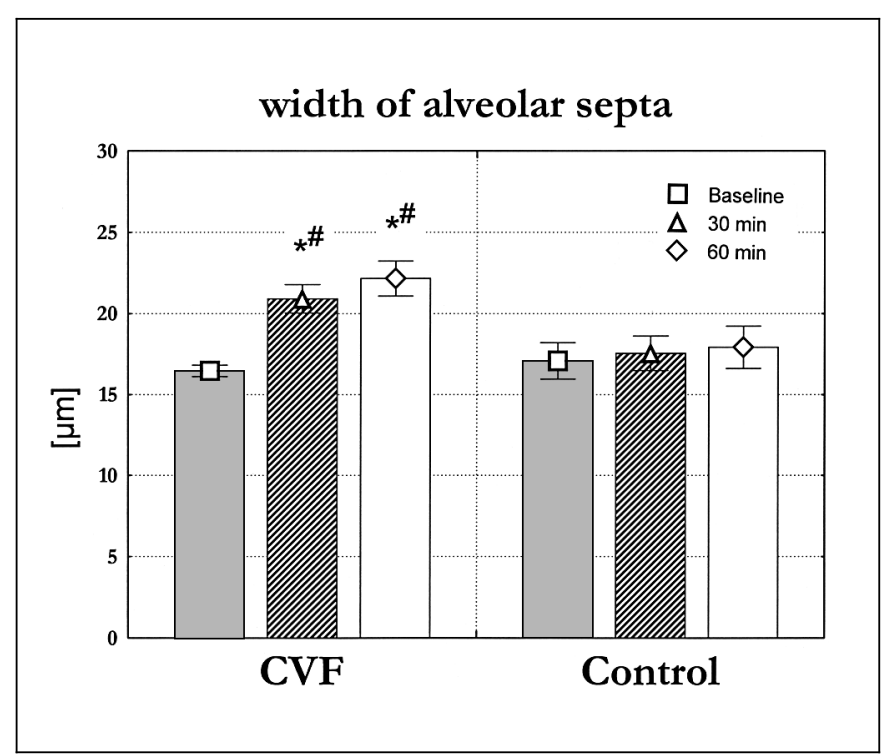

J Vasc Res 1999;36:289-298 


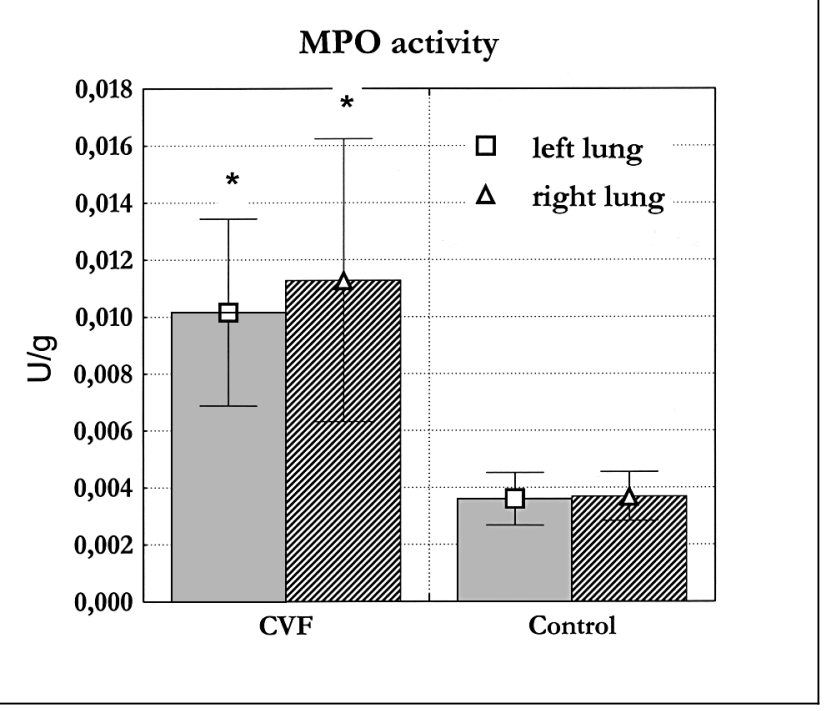

Fig. 4. Activity of MPO in the lung. Values are means \pm SEM; CVF $(\mathrm{n}=8)$, control $(\mathrm{n}=8) ; * \mathrm{p}<0.05 \mathrm{CVF}$ vs. control.

\section{Discussion}

Leukocytes play a decisive role in the pathogenesis of acute inflammation in many tissues, including the lungs. The early state of acute pulmonary injury is often characterized by large numbers of neutrophils residing in the vascular, interstitial and intra-alveolar spaces of the lungs $[22,23]$. These cells are thought not only to provide a host defense function but, unfortunately, they can also injure lung tissue by the release of toxic products including proteases and reactive oxygen species. It has been shown in various models that inhibition of leukocyte function or leukocyte adhesion prevents lung injury. However, the mechanisms by which blocking of leukocyte adhesion prevents lung injury are less clear.

In the systemic microcirculation neutrophils adhere to the walls of postcapillary venules and subsequently migrate into the tissue at this site [13]. Inhibition of leukocyte rolling or leukocyte sticking to the venular wall interrupts this sequence and prevents subsequent migration of the activated leukocytes and therefore injury [24, 25].

It has been suggested that the alveolar capillaries are the site of leukocyte interaction with the microvasculature in the lungs $[7,12,26,27]$. The mechanisms involved in leukocyte sequestration in the capillaries include the biophysical properties of leukocytes, especially the size of the cell and the deformability along with the cross-section of the capillaries and the hydrodynamic forces in the capillaries. Previous studies have shown that neutrophils with diameters of approximately $6.4 \mu \mathrm{m}$ have to change their shape in order to pass through the alveolar capillaries with distinctly smaller diameters $(6.0 \mu \mathrm{m})$. This results in a prolonged capillary transit time of the cells compared to red cells [28]. Since leukocyte deformability strongly depends on cell activation, i.e. the neutrophils become stiffer when activated, prolonged transit times of leukocytes during their passage through the alveolar capillaries or plugging of the cell within the capillary would be the result $[11,29]$. If these activated leukocytes, stagnant in the capillary, come into direct contact with the endothelium or interstitial fibroblasts - and there is evidence that they do so [30] -, migration of the neutrophils into the interstitial space of the lungs or into the alveolar space would be possible without involvement of any adhesion molecules. However, it has been shown that blocking of adhesion molecules inhibits leukocyte sequestration in the lungs and prevents lung injury. This raises the question whether leukocyte adhesion does occur in pulmonary venules and/ or arterioles, or whether adhesion molecules are involved in leukocyte sequestration in the capillaries.

Our study provides quantitative information describing the microhemodynamics, kinetics and location of leukocyte sequestration and the development of interstitial lung edema, occurring after complement activation by a bolus injection of cobra venom factor. In parallel to the decrease in the number of circulating neutrophils in arterial blood counts, leukocytes were sequestered in all parts of the pulmonary microcirculation. Quantitatively, most leukocytes were sequestered in alveolar capillaries, but it has been shown that leukocytes also adhere to the endothelium of pulmonary venules and arterioles after systemic complement activation.

Despite higher red blood cell velocities in venules as compared to arterioles, leukocyte adhesion was more pronounced in venules. A different distribution of endothelial adhesion molecules in arterioles and venules may account for this finding [18]. The observation of higher red blood cell velocities in venules as compared to arterioles can be explained by the dependence of blood flow on gravity and alveolar pressure in the lung, as described by West et al. [31], and by the hydrodynamics in collapsible vessels, as described by Permutt et al. [21]. During inspiration, the field of observation in the lung is under the condition of zone 2, i.e. alveolar pressure is higher than the pressure in the venules and the venular part of the capillary network. Some capillaries collapse, regional blood flow decreases, resulting in a 'vascular waterfall', 
with low or even negative transmural pressure in the venular compartment. As a result, the vessel cross-section decreases, the blood flow velocity increases and may be higher than in arterioles. In addition, a shift of blood from the capillary to the venular compartment during inspiration may increase flow and velocity in the venules.

Leukocyte retention was quantified by identifying and measuring leukocytes not moving for at least $5 \mathrm{~s}$. A 5second period is long enough to differentiate between rolling mediated by selectin adhesion molecules where leukocytes travel at velocities of 50-200 $\mu \mathrm{m} / \mathrm{s}$ and remain stationary for not more than $0.06 \mathrm{~s}$ and sticking mediated by integrin adhesion molecules. In alveolar capillaries, temporarily arrested leukocytes stop at distinct sites of the alveolar capillary networks usually for less than $1 \mathrm{~s}$, whereas another population of cells is retained by a different mechanism for longer periods of time [18]. Previous experiments have shown that inhibition of selectin-mediated adhesion results in a large reduction of leukocyte rolling in pulmonary arterioles and venules as well as in a reduction of the temporary arrest in alveolar capillaries, but has no effect on sticking as quantified according to the 5 -second criterion [16]. However, it has been reported that temporary adherence may occur in venules of the systemic circulation for variable periods of time ranging between 1 and more than $60 \mathrm{~s}$ [32]. Therefore, the criteria used to identify an adherent leukocyte differ among laboratories, with stationary state ranging between 1 and $60 \mathrm{~s}$ [13]. To determine the upper time range of leukocyte adhesion, we measured leukocyte retention in 2 control animals, within two subsequent observation periods prolonged to $45 \mathrm{~s}$. Observations were separated by a 30-second recovery period. In each animal 2 arterioles, 2 venules and 4 alveolar capillary networks were measured. At the end of prolonged inspirations, the blood pressure was reduced by $15 \%$ and the heart rate by $30 \%$, an effect that is explained by venous congestion due to a 'Valsalva'- like maneuver. Microcopically, red blood cell velocity decreased slightly as well. In arterioles ( $n=4$ observations), venules $(n=4)$ and alveolar capillary networks $(n=4), 97$, 98 and $100 \%$ of leukocytes, sticking for the first $5 \mathrm{~s}$, remained stationary until the end of the observation (30$55 \mathrm{~s}$ ). Except in 1 arteriole and 1 venule where a difference of 1 leukocyte occurred, the number of sticking leukocytes in the vessel or alveolar network were identical for the two subsequent observation periods. These data indicate that leukocytes classified as stickers according to a 5-second criterion represent cells adherent for longer periods of time.

Leukocyte Kinetics in the Lung after

Complement Activation
Concomitant to leukocyte sequestration after injection of CVF, alveolar septa, measured microscopically, were enlarged and gas exchange was slightly reduced. However, microhemodynamic conditions in pulmonary microvessels and macrohemodynamics were not significantly altered. At the end of the experiments, the lungs showed an increase of MPO activity.

The effects of complement activation on lung injury have been studied by different groups previously. Webster et al. [33], and Larsen et al. [34] have shown that $\mathrm{CVF}$, fragments of the activated complement factor C5 (C5f) or zymosan-activated plasma (ZAP) administered intravascularly to rabbits caused acute neutropenia along with sequestration of neutrophils within the pulmonary vasculature. However, CVF or C5f alone did not induce lung injury, as determined by extravasation of radioactive labeled albumin. When combining CVF with an episode of hypoxia, a significant increase of radioactively labeled albumin in the lavage fluid and a decrease in $\mathrm{PaO}_{2}$ occurred and neutrophils were observed in the air spaces histologically [34]. Doerschuk et al. [35] have shown that infusion of ZAP in rabbits results in rapid sequestration of radiolabeled neutrophils in the lungs if leukocytes were injected intravenously or into the systemic microvasculature after intra-arterial infusion of the cells. In a subsequent study, they showed that neutrophil sequestration after ZAP infusion was due to a rapid decrease in PMN deformability induced by a redistribution of actin from the central to the submembrane regions of the neutrophils [9]. A mild epithelial and endothelial injury was verified by the clearance of intratracheally administered fluorescein dextran and by the accumulation of colloidal carbon in the pulmonary microvasculature after the same stimulus. This injury could be prevented by depleting the animals of PMN or by pretreatment with indomethacin [36]. Pretreatment of the rabbits with anti-CD18 monoclonal antibody showed that the initial accumulation of neutrophils in the lungs could not be prevented, but the accumulation of neutrophils was largely inhibited after 15 min of ZAP infusion [37]. In the rat, complement activation by intravenous CVF results in acute lung injury, as reflected by an increase in pulmonary microvascular permeability, as well as by morphological evidence of damage to the pulmonary vascular endothelium [38]. This injury is dependent on neutrophils and toxic oxygen metabolites [38]. Permeability changes and hemorrhage in that model were reduced by pretreatment with antibodies directed against adhesion molecules CD18 [6], CD11a, CD11b, ICAM1 [39], P-selectin [40] and L-selectin [41]. Interestingly, if CVF was injected in P-selectin-, ICAM-1- or P-selectin/

J Vasc Res 1999;36:289-298 295 
ICAM1-deficient mice, mutant mice did not show a reduction in neutrophil sequestration or lung injury in contrast to wild-type mice treated with the respective antibodies [42].

Our data confirm findings that complement activation leads to an accumulation of leukocytes in the lungs and to mild lung injury. There is strong evidence that all stimuli, infusion of ZAP, CVF or C5f, activate circulating leukocytes, thus reducing their deformability and resulting in accumulation of the cells in pulmonary capillaries. However, none of these studies answered the question whether activation of complement leads to adhesion of leukocytes in extracapillary vessels, especially in postcapillary venules, as it would be expected in microvascular beds in the systemic circulation. In the only study that directly investigated leukocyte kinetics during acute inflammation, sequestration of neutrophils was found almost exclusively in capillaries [7], where the transit of leukocytes labeled in vitro was microscopically investigated in a microscopic field containing an arteriole, a venule and the connecting capillary network after administration of $\mathrm{C} 5 \mathrm{f}$ into either the airways or the pulmonary arteries of anesthetized dogs. Concerning the absence of leukocyte adhesion in arterioles and venules, their findings differ from ours. Besides possible differences between species or the stimulus used, the major difference between our studies is the labeling technique of leukocytes. Lien et al. [7] used neutrophils that had been separated by plasma-Percoll gradients in vitro. Since in vitro separation of leukocytes may induce activation and therefore shedding of L-selectin adhesion molecules, these cells might lose their ability to interact with the vascular endothelium of venules and arterioles [16-18, 43, 44]. In a subsequent study, Downey et al. [28] employed morphometric techniques after local instillation of C5f in rabbit lungs. They again found neutrophil sequestration predominantly in the capillaries of the interalveolar septa. The number of neutrophils sequestered in the capillary bed per unit surface area of basal lamina they found was 10 -fold higher than the number sequestered in the arteriolar or venular compartment. Considering that the surface area of the capillary bed exceeds the surface of the venular or arteriolar compartment by far, they concluded that migration from extracapillary vessels must be negligible. It seems very difficult to compare the morphometric data of the latter study with our quantitative in vivo microscopic data. It has to be noted that these authors found leukocytes within the venular and arteriolar compartment. However, the mean diameter of the venules and arterioles analyzed in that study is not documented. Since vessel diameters were pos- sibly underestimated in histologic sections after intratracheal fixation of the lungs, it cannot be excluded that vessels classified as arterioles and venules represent small arteries and venules with an in vivo diameter of larger than $50-100 \mu \mathrm{m}$. Each arteriole or venule with $100 \mu \mathrm{m}$ in diameter (4th or 5th vessel order) supplies approximately 150 terminal vessels with diameters of $20 \mu \mathrm{m}$ [45] (which can hardly be differentiated from a capillary in a histologic section). Therefore, it may be speculated whether Downey et al. [26] underestimated the number of postcapillary venules and precapillary arterioles including the neutrophils within these vessels in favor of the capillary compartment.

Intravital microscopic studies in skeletal muscle of hamsters or in mesenteric vessels have shown that leukocyte recruitment to sites of injury follows three steps, all mediated at least in part by adhesion molecules. First, leukocytes roll along the endothelium, a phenomenon dependent on L-selectin, an adhesion molecule expressed on the surface of leukocytes and P-selectin which is expressed on endothelial cells after stimulation. Second, leukocytes firmly adhere to the endothelial cells, a phenomenon involving $\beta 2$ integrins (CD18/CD11) and ICAM1 adhesion molecules. Third, the leukocytes extravasate if there is a chemotactic gradient to the tissue. However, these mechanisms have been described almost exclusively in postcapillary venules, under special circumstances in arterioles, but not in capillaries [13,44].

Our finding of leukocyte sticking in venules and arterioles support the possibility that the same mechanisms may be valid also in the lungs. The protective effect of anti-adhesion therapy in different models of lung injury may be explained by inhibiting leukocyte-endothelium interactions in venules and possibly arterioles. Nevertheless, the situation may be more complex. A very dense network of alveolar capillaries, with diameters below the diameter of leukocytes, promotes retention of leukocytes even under physiological conditions. Activation of leukocytes leads to stiffening of the cells. Decreased leukocyte deformability, together with swelling of endothelial cells, further promotes leukocyte retention in the lung capillaries during inflammation. Doerschuk et al. [37] have postulated that this is the initial, CD18-independent mechanism of leukocyte sequestration, whereas the following step, firm adhesion and extravasation, is CD18 dependent [37]. In addition, there is increasing evidence that adhesion molecules are involved in leukocyte adhesion, also in capillaries. Recently, we were able to show that inhibition of the selectin adhesion molecules by fucoidin reduces leukocyte rolling in pulmonary arterioles and 
venules and leukocyte endothelial interactions in alveolar capillaries [16].

In summary there is strong evidence that most of all activated leukocytes after a chemotactic stimulus were sequestered in alveolar capillaries. A presumably smaller fraction of leukocytes roll and stick to the endothelium of pulmonary arterioles and venules. Since inhibition of adhesion molecules, i.e. selectins as well as integrins, protects the lungs fully or in part from injury, two mechanisms are conceivable. Either adhesion molecules are involved in the leukocyte-vascular interaction and emi- gration in alveolar capillaries or leukocytes roll, stick and emigrate predominantly from the pulmonary arteriolar or venular site.

\section{Acknowledgement}

We thank Prof. Dr. Drs. h.c. mult. K. Messmer and Prof. Dr. Dr. h.c. K. Peter for continuous support and S. Galland for technical assistance.

\section{References}

1 Tennenberg SD, Clardy CW, Bailey WW, Solomkin JS: Complement activation and lung permeability during cardiopulmonary bypass. Ann Thorac Surg 1990;50:597-601.

2 Turnage RH, Guice KS, Oldham KT: Pulmonary microvascular injury following intestinal reperfusion. New Horiz 1994;2:463-475.

3 Martin MA, Silverman HJ: Gram-negative sepsis and the adult respiratory distress syndrome. Clin Infect Dis 1992;14:1213-1228.

4 Mulligan MS, Paulson JC, DeFrees S, Zheng ZL, Lowe JB, Ward PA: Protective effects of oligosaccharides in P-selectin-dependent lung injury. Nature 1993;364:149-151.

5 Mulligan MS, Miyasaka M, Ward PA: Protective effects of combined adhesion molecule blockade in models of acute lung injury. Proc Assoc Am Physicians 1996;108:198-208.

6 Mulligan MS, Varani J, Warren JS, Till GO, Smith CW, Anderson DC, Todd RF, Ward PA: Roles of beta 2 integrins of rat neutrophils in complement- and oxygen radical-mediated acute inflammatory injury. J Immunol 1992; 148:1847-1857.

7 Lien DC, Henson PM, Capen RL, Henson JE, Hanson WL, Wagner WW Jr, Worthen GS: Neutrophil kinetics in the pulmonary microcirculation during acute inflammation. Lab Invest 1991;65:145-159.

8 Shaw JO, Henson PM, Henson J, Webster RO: Lung inflammation induced by complementderived chemotactic fragments in the alveolus. Lab Invest 1980;42:547-558.

9 Inano H, English D, Doerschuk CM: Effect of zymosan-activated plasma on the deformability of rabbit polymorphonuclear leukocytes. J Appl Physiol 1992;73:1370-1376.

10 Downey GP, Worthen GS, Henson PM, Hyde DM: Neutrophil sequestration and migration in localized pulmonary inflammation. Am Rev Respir Dis 1993;147:168-176.

11 Worthen GS, Schwab B, Elson EL, Downey GP: Mechanics of stimulated neutrophils: Cell stiffening induces retention in capillaries. Science 1989;245:183-186.

12 Hogg JC, Doerschuk CM: Leukocyte traffic in the lung. Annu Rev Physiol 1995;57:97-114.
13 Granger DN, Kubes P: The microcirculation and inflammation: Modulation of leukocyteendothelial cell adhesion. J Leukoc Biol 1994; 55:662-675.

14 Kuhnle GE, Reichenspurner H, Lange $\mathrm{T}$, Wagner F, Groh J, Messmer K, Goetz AE: Microhemodynamics and leukocyte sequestration after pulmonary ischemia and reperfusion in rabbits. J Thorac Cardiovasc Surg 1998;115: 937-944.

15 Gebb SA, Graham JA, Hanger CC, Godbey PS, Capen RL, Doerschuk CM, Wagner WW Jr: Sites of leukocyte sequestration in the pulmonary microcirculation. J Appl Physiol 1995;79: 493-497.

16 Kuebler WM, Kuhnle GE, Groh J, Goetz AE: Contribution of selectins to leucocyte sequestration in pulmonary microvessels by intravital microscopy in rabbits. J Physiol (Lond) 1997; 501:375-386.

17 Kuebler WM, Kuhnle GE, Groh J, Goetz AE: Leukocyte kinetics in pulmonary microcirculation: Intravital fluorescence microscopic study. J Appl Physiol 1994;76:65-71.

18 Kuhnle GE, Kuebler WM, Groh J, Goetz AE: Effect of blood flow on the leukocyte-endothelium interaction in pulmonary microvessels. Am J Respir Crit Care Med 1995;152:12211228.

19 Kuhnle GE, Leipfinger FH, Goetz AE: Measurement of microhemodynamics in the ventilated rabbit lung by intravital fluorescence microscopy. J Appl Physiol 1993;74:1462-1471.

20 Kuebler WM, Abels C, Schuerer L, Goetz AE: Measurement of neutrophil content in brain and lung tissue by a modified myeloperoxidase assay. Int J Microcirc Clin Exp 1996;16:89_ 97.

21 Permutt S, Riley RL: Hemodynamics of collapsible vessels with tone: The vascular waterfall. J Appl Physiol 1963;18:924-932.

22 Hammerschmidt DE, Weaver LJ, Hudson LD, Craddock PR, Jacob HS: Association of complement activation and elevated plasma-C5a with adult respiratory distress syndrome. Pathophysiological relevance and possible prognostic value. Lancet 1980;i:947-949.
23 Tate RM, Repine JE: Neutrophils and the adult respiratory distress syndrome. Am Rev Respir Dis 1983;128:552-559.

24 Bevilacqua MP, Nelson RM, Mannori G, Cecconi O: Endothelial-leukocyte adhesion molecules in human disease. Annu Rev Med 1994; 45:361-378.

25 Butcher EC: Leukocyte-endothelial cell recognition: Three (or more) steps to specificity and diversity. Cell 1991;67:1033-1036.

26 Downey GP, Worthen GS, Henson PM, Hyde DM: Neutrophil sequestration and migration in localized pulmonary inflammation: Capillary localization and migration across the interalveolar septum. Am J Respir Crit Care Med 1993;147:168-176.

27 Hogg JC: Neutrophil kinetics and lung injury. Physiol Rev 1987;67:1249-1295.

28 Doerschuk CM, Beyers N, Coxson HO, Wiggs B, Hogg JC: Comparison of neutrophil and capillary diameters and their relation to neutrophil sequestration in the lung. J Appl Physiol 1993;74:3040-3045.

29 Downey GP, Doherty DE, Schwab B, Elson EL, Henson PM, Worthen GS: Retention of leukocytes in capillaries: Role of cell size and deformability. J Appl Physiol 1990;69:17671778.

30 Behzad AR, Chu F, Walker DC: Fibroblasts are in a position to provide directional information to migrating neutrophils during pneumonia in rabbit lungs. Microvasc Res 1996;51:303-316.

31 West JB, Dollery CT, Naimark A: Distribution of blood flow in isolated lung: Relation to vascular and alveolar pressures. J Appl Physiol 1964;19:713-724.

32 House SD, Lipowsky HH: Dynamics of leukocyte-endothelium interactions in the splanchnic microcirculation. Microvasc Res 1991;42: 288-304.

33 Webster RO, Larsen GL, Mitchell BC, Goins AJ, Henson PM: Absence of inflammatory lung injury in rabbits challenged intravascularly with complement-derived chemotactic factors. Am Rev Respir Dis 1982;125:335-340. 
34 Larsen GL, Webster RO. Worthen GS, Gumbay RS, Henson PM: Additive effect of intravascular complement activation and brief episodes of hypoxia in producing increased permeability in the rabbit lung. J Clin Invest 1985; 75:902-910.

35 Doerschuk CM, Allard MF, Hogg JC: Neutrophil kinetics in rabbits during infusion of zymosan-activated plasma. J Appl Physiol 1989; 67:88-95.

36 Gie RP, Doerschuk CM, English D, Coxson HO, Hogg JC: Neutrophil-associated lung injury after the infusion of activated plasma. J Appl Physiol 1991;70:2471-2478.

37 Doerschuk CM: The role of CD18-mediated adhesion in neutrophil sequestration induced by infusion of activated plasma in rabbits. Am J Respir Cell Mol Biol 1992; 7:140-148.
38 Till GO, Johnson KJ, Kunkel RG, Ward PA: Intravascular activation of complement and acute lung injury: Dependency on neutrophils and toxic oxygen metabolites. J Clin Invest 1982;69:1126-1135.

39 Mulligan MS, Smith CW, Anderson DC, Todd RF III, Miyasaka M, Tamatani T, Issekutz TB, Ward PA: Role of leukocyte adhesion molecules in complement-induced lung injury. J Immunol 1993;150:2401-2406.

40 Mulligan MS, Polley MJ, Bayer RJ, Nunn MF, Paulson JC, Ward PA: Neutrophil-dependent acute lung injury. Requirement for P-selectin (GMP-140). J Clin Invest 1992;90:1600-1607.

41 Mulligan MS, Miyasaka M, Tamatani T, Jones ML, Ward PA: Requirements for L-selectin in neutrophil-mediated lung injury in rats. J Immunol 1994;152:832-840.
42 Doerschuk CM, Quinlan WM, Doyle NA, Bullard DC, Vestweber D, Jones ML, Takei F, Ward PA, Beaudet AL: The role of P-selectin and ICAM-1 in acute lung injury as determined using blocking antibodies and mutant mice. J Immunol 1996;157:4609-4614.

43 Kishimoto KT, Jutila MA, Berg EL, Butcher EC: Neutrophil Mac-1 and Mel-14 adhesion proteins inversely regulated by chemotactic factors. Science 1989;245:1238-1241.

44 Von Andrian UH, Chambers JD, McEvoy LM, Bargatze RF, Arfors KE, Butcher EC: Two-step model of leukocyte-endothelial cell interaction in inflammation: Distinct roles for LECAM-1 and the leukocyte beta 2 integrins in vivo. Proc Natl Acad Sci USA 1991;88:7538-7542.

45 Kuhnle GEH, Groh J, Leipfinger FH, Kuebler WM, Goetz AE: Quantitative analysis of network architecture, and microhemodynamics in arteriolar vessel trees of the ventilated rabbit lung. Int J Microcirc Clin Exp 1993;12:313324. 